\title{
REVIEW \\ Oxidative stress in spinal cord injury and antioxidant-based intervention
}

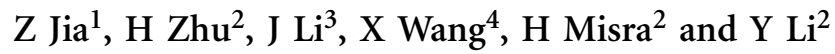

Study design: Literature review.

Objectives: Spinal cord injury (SCI) remains a major public health issue in developed countries as well as worldwide. The pathophysiology of $\mathrm{SCl}$ is characterized by an initial primary injury followed by secondary deterioration. Although the etiology and pathogenesis of SCI remain to be fully understood, it has been suggested that reactive oxygen species (ROS) and oxidative stress have a significant role in the pathophysiology of SCI. Thus, alleviating oxidative stress may be an effective strategy for therapeutic intervention of SCl. The aim of this review was to describe (i) the sources of ROS as well as the major antioxidant defenses with particular attention being paid to lipid peroxidation; (ii) the biomarkers of oxidative stress in $\mathrm{SCl}$ and (iii) the neuroprotective effects of various compounds with antioxidative properties in animal models of SCl.

Methods: PubMed, one of the most comprehensive biomedical databases, was searched from 1976-2011. All relevant papers were read by title, abstract and full-length article.

Results: Oxidative stress is considered a hallmark of injury of SCl. Thus, alleviating oxidative stress may be an effective way of therapeutic intervention of SCl. Two of these agents, the glucocorticoid steroid methylprednisolone and the non-glucocorticoid 21-aminosteroid tirilazad, have been shown to possess significant antioxidant activities and improve recovery of SCl patients in clinical trials. Other promising botanical compounds and their molecular targets and mechanisms of action with regard to potential protection against SCl were also described. These include carotenoids and phenolic compounds.

Conclusion: ROS and oxidative stress have a significant role in the pathophysiology of SCl. Alleviating oxidative stress is be an effective strategy for therapeutic intervention of SCl. Extensive research over the past several decades has identified numerous bioactive compounds that have antioxidative stress benefits in animal models of SCl. Thus, continued studies on bioactive compounds with ROS-scavenging capacity may lead to the development of effective antioxidant-based modalities for treating SCI in human subjects. Spinal Cord (2012) 50, 264-274; doi:10.1038/sc.2011.111; published online 11 October 2011

Keywords: spinal cord injury; oxidative stress; biomarkers; bioactive compounds

\section{INTRODUCTION}

Spinal Cord injury (SCI) is damage or trauma to the spinal cord resulting in paralysis and loss of sensation. There are $\sim 400000$ spinally injured patients in the United States with over 14000 new injuries occurring each year. ${ }^{1}$ SCI imposes high physical and psychological effects not only to the individual, but also to the family and the society. Depending on the location of the injury, the symptoms of SCI may include loss of movement, sensation to feel heat, cold and touch, loss of bowel or bladder control and exaggerated reflex activities as well as pain. ${ }^{1}$

The pathophysiology of SCI is characterized by an initial primary injury followed by a secondary phase of injury in which oxidative stress is a critical component. Primary injury results immediately from the initial trauma, which includes contusion, damage to blood vessels and axonal shearing. In contrast, secondary injury is an indirect result from primary injury initiated by trauma. It occurs in hours, days and weeks following the primary injury. Secondary injury occurs not only at the site of the initial primary injury, but also results in spreading of the lesion to adjacent, otherwise uninjured tissue. Because secondary injury to spinal cord has an important role in disease progression, it is important to understand the molecular and cellular events leading to the secondary lesion of SCI.

Although the etiology and pathogenesis of SCI remain to be further elucidated, extensive studies over the last two decades have suggested that increased formation of reactive oxygen species (ROS) and the consequent oxidative stress are important events associated with SCI. The neurons and glia in the central nervous system including spinal cord are particularly prone to oxidative and electrophilic stress due to many factors, including a high content of polyunsaturated fatty acids, a high rate of oxidative metabolic activity, intense production of reactive oxygen metabolites and relatively low antioxidant capacity. ${ }^{2,3}$ Indeed, oxidative stress is considered a hallmark of the secondary phase of injury of SCI. ${ }^{2,3}$ Thus, alleviating oxidative stress may be an effective way of therapeutic intervention of SCI.

\section{METHODS}

We searched MEDLINE (PubMed) and reference lists of the included articles published mainly between 1976 and 2011 using the following key words: SCI, oxidative stress, biomarkers, antioxidant, bioactive compounds and intervention.

${ }^{1}$ Department of Biology, University of North Carolina at Greensboro, Greensboro, NC, USA; ${ }^{2}$ Division of Biomedical Sciences, Edward Via College of Osteopathic Medicine, Virginia Tech Corporate Research Center, Blacksburg, VA, USA; ${ }^{3}$ TCM Classics Research Institute, KB Nijmegen, The Netherlands and ${ }^{4}$ Shandong University of Traditional Chinese Medicine, Jinan, China

Correspondence: Dr Z Jia, Department of Biology, University of North Carolina at Greensboro, Greensboro, 321 Mclver street, 312 Eberhart Bldg, Greensboro, NC 27412, USA. E-mail: z_jia@uncg.edu or Dr Y Li, Division of Biomedical Sciences, Edward Via College of Osteopathic Medicine, Virginia Tech Corporate Research Center, Blacksburg, VA 24060, USA.

E-mail: yli@vcom.vt.edu

Received 28 December 2010; revised and accepted 1 September 2011; published online 11 October 2011 


\section{RESULTS}

ROS and oxidative stress in SCI

Reactive oxygen species (ROS). Molecular oxygen is an essential element of life, yet incomplete reduction or excitation of oxygen during aerobic metabolism generates ROS. ROS include superoxide, hydroxyl radical, singlet oxygen and hydrogen peroxide (Figure 1). Superoxide is the one-electron reduction product of molecular oxygen. If two electrons are transferred, the product is hydrogen peroxide. Transition metal ions, such as $\mathrm{Fe}^{2+}$ or $\mathrm{Cu}^{+}$are capable of transferring a third electron to hydrogen peroxide, causing lysis of the $\mathrm{O}-\mathrm{O}$ bond generating the hydroxyl radical, one of the most potent oxidants known. In phagocytes, superoxide is produced in large quantities by the enzyme nicotinamide adenine dinucleotide phosphate oxidase for use in oxygen-dependent killing mechanisms. ${ }^{4}$ Superoxide has also been implicated in the mechanisms of aging and the peroxidation of lipids. Hydrogen peroxide is not a free radical but is nonetheless a damaging species because of its ability to penetrate biological membranes. Hydrogen peroxide is toxic to cells and can lead to further free-radical generation. For example, hydrogen peroxide reacts with reduced transition metals to form the highly reactive hydroxyl radical, which readily causes damage to DNA and other biological molecules. ${ }^{5-7}$ Previous studies have demonstrated that the formation of ROS including hydroxyl radical, superoxide and hydrogen peroxide immediately after central nervous system injury may contribute to the pathogenesis of SCI. ${ }^{8,9}$

Source of ROS. Production of ROS under physiological conditions is important for normal cellular redox reactions. However, excessive generation of free radicals under pathophysiological conditions such as SCI can greatly enhance the production of ROS. Mitochondrias are the major source of cellular ROS because they consume about $90 \%$ of the oxygen utilized by cells during the oxidative phosphorylation under physiological conditions. The mitochondrial dysfunction results in further increased formation of ROS. Structural and functional alterations of the mitochondria have been found in a SCI mouse model. ${ }^{10} \mathrm{SCI}$ results in a cascade of secondary events including release of excitatory amino acids and disruption of calcium homeostasis, which may further cause the mitochondrial dysfunction and augmented ROS formation, leading to neuronal cell death. ${ }^{2}$ In addition to the mitochondria, phagocytic cells such as neutrophils and macrophages also contribute to the generation of ROS following experimental SCI. ${ }^{4}$ After traumatic SCI, phagocytic cells exhibit a marked increase in oxygen consumption and generation of superoxide from membranesassociated nicotinamide adenine dinucleotide phosphate oxidase. The enzyme complex transfers electrons from nicotinamide adenine dinucleotide phosphate oxidase at the cytosolic side of the membrane to molecular oxygen at the other side of the membrane resulting in the production of extracellular superoxide. ${ }^{4}$ Other potential biological sources of ROS associated with the pathogenesis of traumatic SCI include soluble cell constituents, cytosolic oxidases, transition metals, lysosomes, peroxisomes and endoplasmic reticulum. For example, there are many cytosolic enzymes that can generate ROS via reduction of molecular oxygen in their catalytic cycles. The most notable one is xanthine oxidase, which can directly reduce molecular oxygen to superoxide and hydrogen peroxide. ${ }^{11}$

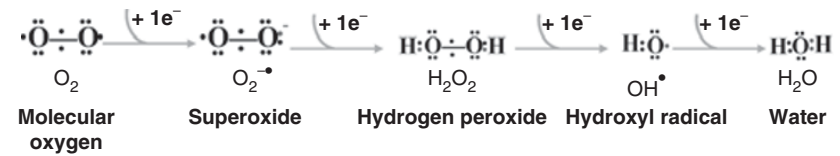

Figure 1 Schematic illustration of the formation of reactive oxygen species.
Antioxidant defenses. ROS participate in physiological processes, such as cell signaling. However, excessive generation of ROS under pathophysiological conditions, including SCI may result in oxidative stress. To control ROS, aerobic organism has utilized several antioxidative mechanisms including enzymatic and non-enzymatic antioxidants ${ }^{12}$ (Figure 2). Non-enzyme low molecular weight antioxidant compounds include cellular glutathione, vitamins $\mathrm{C}$ and $\mathrm{E}, \beta$-carotene and uric acid. The antioxidant enzymes include superoxide dismutase (SOD), catalase, glutathione reductase and glutathione peroxidase among others. SOD catalyzes the dismutation of superoxide to $\mathrm{H}_{2} \mathrm{O}_{2}$ in the following reaction: $\mathrm{O}_{2}{ }^{-\cdot}+\mathrm{O}_{2}{ }^{-\cdot}+2 \mathrm{H}^{+} \rightarrow \mathrm{H}_{2} \mathrm{O}_{2}+\mathrm{O}_{2}$. Mammalian cells contain three forms of SOD, MnSOD, Cu,ZnSOD and extracellular SOD. MnSOD is most abundant in the mitochondria, whereas $\mathrm{Cn}, \mathrm{ZnSOD}$ predominant in the cytoplasm. ${ }^{13}$ Catalase is a major antioxidant enzyme that catalyzes the decomposition of $\mathrm{H}_{2} \mathrm{O}_{2}$ to $\mathrm{H}_{2} \mathrm{O}$. Glutathione peroxidase is another major enzyme for decomposing $\mathrm{H}_{2} \mathrm{O}_{2}$.

The elimination of ROS following SCI is particularly controlled by cellular antioxidant glutathione and Cu,ZnSOD. ${ }^{14}$ Lucas, et al. ${ }^{14}$ examined the effects of glutathione treatment on lipid peroxidation after SCI in a rat contusion injury model. The results suggested that elevation of levels of glutathione by irrigation with $\delta$-glutamylcysteine conferred significant protection against lipid peroxidation after SCI, suggesting that glutathione augmentation may be an effective strategy for curtailment of lipid peroxidation-mediated damage in SCI. ${ }^{14}$ Mutations in the gene for $\mathrm{Cu}, \mathrm{ZnSOD}$ have been identified in familial amyotrophic lateral sclerosis (ALS), a disease characterized by damage and loss of neurons in both the brain and the spinal cord. ${ }^{15}$ Transgenic mice overexpressing wide-type $\mathrm{Cu}, \mathrm{ZnSOD}$ gene show resistance to $\mathrm{SCI}$, indicating that $\mathrm{Cu}, \mathrm{ZnSOD}$ has an important role in protecting against spinal neuron death. ${ }^{16}$

$\mathrm{NAD}(\mathrm{P}) \mathrm{H}$ :quinone oxidoreductase 1 (NQO1) is another important antioxidant enzyme that has recently been demonstrated to has a protective role in electrophilic stress underlying spinal cord damage. ${ }^{17,18}$ NQO1 catalyzes the two electron reduction of electrophilic quinone compounds, thus limiting the formation of semiquinone radicals through one electron reduction, and the subsequent generation of ROS. ${ }^{18,19}$ NQO1 is also able to maintain the cellular levels of ubiquinol and vitamin E, two important biological antioxidants involved in the detoxification of ROS. ${ }^{17,20}$ Therefore, the coordinated actions of a spectrum of cellular antioxidants and probably other cytoprotective proteins ensure efficient detoxification of ROS and electrophilic species that participate in the pathogenesis of SCI.

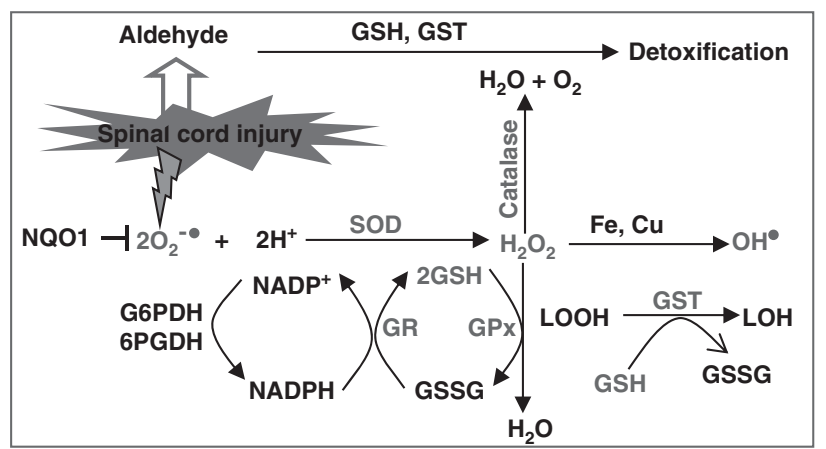

Figure 2 ROS and their detoxification by cellular antioxidants. GPx, glutathione peroxidase; GR, glutathione reductase; GSH, reduced glutathione; GSSG, oxidized form of glutathione; GST, glutathione S-transferase; G6PDH, glucose-6-phosphate dehydrogenase; 6PGDH, 6-phosphogluconate dehydrogenase; LOH, lipid alcohol; NQO1, NAD(P)H:quinone oxidoreductase 1; SOD, superoxide dismutase. 
Lipid peroxidation. High levels of ROS can overwhelm the normal cellular antioxidant defenses leading to several direct and indirect health effects. Direct effects include chain of peroxidation reactions involving lipids and other macromolecules. Indirect effects include modified metabolic pathways and altered pathophysiology of the organ systems due to the oxidative damage. Oxidative stress may occur when ROS are produced faster than they can be removed by cellular defense mechanisms. The main damage to cells results from ROS-induced alteration of macromolecules such as polyunsaturated fatty acids in membrane lipids, proteins, and DNA. Lipid peroxidation is a common and dangerous type of ROS-induced cellular oxidation. It has long been recognized that much of the posttraumatic degeneration of the spinal cord following injury is caused by a secondary injury process, and a significant biochemical event is ROS-induced lipid peroxidation. $^{2}$ In particular, spinal cord is highly vulnerable to oxidative injury owing to its overabundance of polyunsaturated fatty acids that are especially susceptible to peroxidation by ROS. ${ }^{3}$ The importance of ROS and lipid peroxidation in SCI is supported by many experimental and clinical studies demonstrating potential neural protective efficacy of multiple bioactive agents with antioxidant properties. $^{2,21-26}$

Nrf2 as a central regulator of antioxidant defenses. The coordinated elevation of antioxidant enzymes is regulated through a cis-acting element called the antioxidant response element (ARE) within the regulatory region of each of the antioxidant enzyme genes ${ }^{27,28}$ (Figure 3). Transcriptional activation mediated by the ARE is effected by the transcription factor Nrf2. Nrf2 belongs to the CNC family of b-zip transcription factors. The mechanism by which binding of Nrf2 to ARE is induced is still emerging, but likely includes contributions from the repressor of Nrf2 that normally resides in the cytosolic compartment along with the cysteine-rich chaperone Keap1. Keap 1 is an inhibitor of Nrf2 that sequesters it in the cytoplasm. Activation of Nrf2 dissociates Nrf2 from Keap1, allowing for its translocation to the nucleus, where it can interact with the ARE to activate transcription of antioxidant enzyme genes ${ }^{27,28}$ (Figure 3). Activation of Nrf2 and Nrf2mediated antioxidant enzyme gene expression by pro-oxidants, including $\mathrm{H}_{2} \mathrm{O}_{2}$ at moderate non-lethal doses suggests that $\mathrm{Nrf} 2$ signaling may control the adaptive response of neuronal cells to oxidative insults. ${ }^{29}$ This potential Nrf2-mediated adaptive response to oxidative stress is particularly relevant to SCI where the increased level of ROS is constantly generated for a prolonged period of time leading to progressive oxidative stress in secondary injury of SCI. ${ }^{18}$ Systematic increases in Nrf2 and ARE-driven heme oxygenase-1 in the spinal cord of SOD ${ }^{\mathrm{G} 93 \mathrm{~A}}$ rats, an experimental model of ALS, have been reported, ${ }^{30,31}$ which may represent an adaptive response to oxidative stress. In view of the critical involvement of ROS in SCI, upregulation of ARE/Nrf2 pathway to augment endogenous antioxidant defenses may serve as a unique approach to protective/therapeutic intervention of SCI.

\section{Biomarkers of oxidative stress in SCI and their detection}

Biomarkers of ROS and oxidative stress are useful for assessing the pathogenesis and progression of SCI. Biomarkers are defined as characteristics that are objectively measured and evaluated as indicators of normal biological activities, pathogenic processes or pharmacological responses to therapeutic intervention. Because the highly reactive ROS are short lived and difficult to measure directly, indirect measures are most often used to predict the amount of ROS or the extent of oxidative stress occurring in SCI. These include the measurement of glutathione, $\mathrm{Cu}, \mathrm{ZnSOD}$, malondialdehyde (MDA), acrolein and F2-isoprostanes. It is of note that each marker has its own limitation in predicting oxidation in biological systems. As such, it is recommended that at least measurement of two markers should be used.

\section{Glutathione}

Glutathione is the primary low molecular weight thiol antioxidant and co-substrate for several cellular antioxidant enzymes such as glutathione peroxidase and and glutathione transferase. It has a critical role in maintaining the intracellular oxidation-reduction (redox) balance and regulating oxidative stress-induced signaling pathways as well as detoxifying ROS and other reactive aldehydes including acrolein. ${ }^{32}$ It is well known that the central nervous system including the spinal cord has relatively low glutathione levels compared with the other organs, such as the liver, which makes the neurons of the spinal cord especially vulnerable to oxidative stress. ${ }^{1,33-35}$ In the central nervous system, glutathione is present at high concentrations in the astrocytes, which also provide the substrate for glutathione synthesis such as cysteine and dipeptide cysteinyl-glycine to the neighboring neurons. In addition, it is reported that glutathione may also be an important regulatory neuropeptide in the central nervous system. ${ }^{36}$

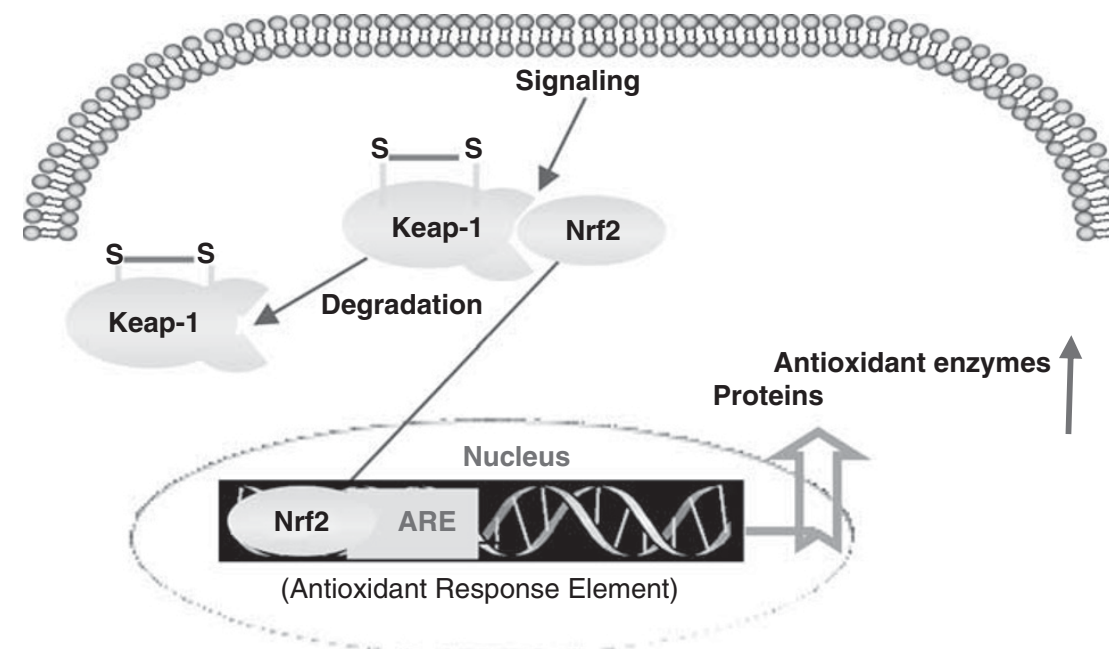

Figure $3 \mathrm{Nrf2}$ binds to the ARE and promotes transcription of antioxidant enzyme genes. 
The synthesis of glutathione from its constituent amino acids involves the actions of two ATP-dependent enzymes, $\gamma$-glutamylcysteine ligase (GCL) and glutathione synthase. GCL, the rate-limiting enzyme in the overall pathway, is a heterodimer composed of a catalytic (GCLC) and a modulatory (GCLM) subunit. GCLC remains all the catalytic activity and GCLM improves the catalytic efficiency. It has been demonstrated that significant decreases in glutathione occurred in spinal segments T5-T9 with the greatest decrease seen at the site of injury and immediately adjacent segments. Between 24 and $48 \mathrm{~h}$, significant decreases in glutathione were also observed throughout the spinal cord from spinal segments $\mathrm{C} 3$ to L4, suggesting that the decrease of glutathione may be a hallmark of oxidative stress that accompanies the prominent inflammatory changes after spinal cord trauma. ${ }^{37}$

There are several chemical ${ }^{38}$ and enzymatic ${ }^{39}$ assays available for determination of glutathione. However, most of these assays lack sensitivity and specificity. Hissin and Hilf ${ }^{40}$ developed a fluorometric method for measuring glutathione. It is based on the reaction of reduced glutathione with $o$-phthalaldehyde to generate a highly fluorescent adduct that is specific for determination of reduced glutathione in rat tissue at $\mathrm{pH} 8.0 .^{41}$ However, the original protocol developed by Hissin and Hilf requires a large amount of tissue samples. As such, it is not practical to routinely use the original protocol for glutathione determination in cultured neuronal cells especially under the conditions of using small volumes and microgram quantities of samples. We have modified the original method of Hissin and Hilf and reported a sensitive and specific assay for determining reduced glutathione status in human neuronal cells. ${ }^{42}$ The modified assay allows the use of small volumes and microgram quantities of samples, and is thus suitable for measuring reduced glutathione in a small number of cells. Given the use of a small sample volume, it also minimizes the presence of interfering substances in the samples.

$\mathrm{Cu}, \mathrm{ZnSOD}$. As mentioned before, mammalian tissues contain three forms of SOD: cytosolic $\mathrm{Cu}, \mathrm{ZnSOD}$, mitochondrial MnSOD and extracellular SOD. The presence of SOD helps dismutate superoxide immediately upon its generation and thus protects cells from superoxide-mediated oxidative damage. Several point mutations in the gene that encodes $\mathrm{Cu}, \mathrm{ZnSOD}$ have been reported in some patients with familial ALS, a disease that is characterized by a loss of motor neurons in both the brain and the spinal cord. ${ }^{43}$ The cytosolic SOD activity, which is primarily $\mathrm{Cu}, \mathrm{ZnSOD}$, was reduced by $38.8 \%$ in some familial ALS patients relative to the control subjects. ${ }^{43,44}$ Furthermore, overexpression of the $\mathrm{Cu}, \mathrm{ZnSOD}$ mutants in rodents emulates clinical and pathological hallmarks of ALS through a possible mechanism of toxic gain of function. ${ }^{21}$ These results indicate a critical involvement of $\mathrm{Cu}, \mathrm{ZnSOD}$ in neurodegeneration in ALS. Cellular Cu,ZnSOD activity can be measured using a commercially available kit from Trevigen, Inc. (Gaithersburg, MD, USA). This kit uses xanthine and xanthine oxidase to generate superoxide, which reacts with 2-(4-iodophenyl)3-(4-nitrophenol)-5-phenyltetrazolium chloride to form formazan blue, which is monitored at $560 \mathrm{~nm}$. The SOD activity is then determined by measuring the \%inhibition of the reaction.

Malondialdehyde (MDA). Lipid peroxidation is a well-defined mechanism of cellular damage and has been implicated in the pathogenesis of many disease processes including SCI. Lipid peroxidation is probably one of the most damaging effects of the ROS in SCI. Once a lipid radical is formed, polyunsaturated lipids can undergo self-propagating chains of peroxidation reactions. Aldehydes including MDA and the highly reactive $\alpha, \beta$-unsaturated acrolein have been shown to be the end products of lipid peroxidation in SCI. There is increasing evidence suggesting that aldehydes may be causally involved in the pathophysiological effects associated with oxidative stress in SCI. ${ }^{45}$

Thiobarbituric acid-reacting substance assay is frequently used for detecting MDA. The standard or sample to be tested is heated with thiobarbituric acid at low $\mathrm{pH}$, and MDA reacts with thiobarbituric acid to produce a MDA-thiobarbituric acid colored complex. Absorbance of the pink chromogen is measured at $532 \mathrm{~nm}$ or by fluorescence at $553 \mathrm{~nm}$. This assay measures both free MDA and protein-bound MDA. The MDA-586 method (Oxis International, Inc., Foster City, CA, USA) is designed to assay free MDA. The assay conditions serve to minimize interference from other lipid peroxidation products, such as 4 -hydroxyalkenal. The principle of the MDA-586 method is based the reaction of a chromogenic reagent, $\mathrm{N}$-methyl-2-phenylindone with MDA at $45^{\circ} \mathrm{C}$. One molecule of MDA reacts with 2 molecules of $N$-methyl-2-phenylindone to yield a stable carbocyanine dye with maximum absorbance at $586 \mathrm{~nm}$.

Acrolein. Acrolein, a major byproduct of oxidative stress and lipid peroxidation, has been implicated in the pathogenesis of SCI. ${ }^{3,46}$ As noted earlier, acrolein is a highly reactive $\alpha, \beta$-unsaturated aldehyde. It is produced as a byproduct of peroxidation of polyunsaturated fatty acids in cell membranes. Acrolein also occurs in the environment as a ubiquitous pollutant that is generated as a byproduct of overheated organic materials. The half-life of acrolein is estimated to be in the order of several hours, which is 100 billion times longer than that of many ROS. As such, acrolein is capable of diffusing to and injuring the otherwise healthy tissue. ${ }^{3,46}$ Acrolein is the most potent electrophile among the unsaturated aldehydes. Acrolein-induced membrane damage may be an important pathogenic mechanism leading to cell death and functional loss in SCI. ${ }^{3,46}$ Previous studies have demonstrated that acrolein is significantly increased following SCI, which is highly toxic to the spinal cord tissue. ${ }^{3,46}$ As early as $4 \mathrm{~h}$ following SCI in vivo, acrolein was found to increase and remain elevated for at least 7 days after injury. ${ }^{3,46}$ Notably, acrolein have been found to be elevated in the brain tissue and in the body fluids of patients with SCI. 3,46 Elevation of acrolein can deplete the cellular antioxidant glutathione as acrolein readily reacts with glutathione. This further compromises the endogenous antioxidant defenses. ${ }^{3,46}$ Multiple studies also suggested that acrolein may represent a potential marker of oxidative stress damage to cellular constituents, especially protein targets in the spinal cord. ${ }^{3,46}$

The presence of protein-bound acrolein could be detected by an antibody (mAb5F6) raised against the acrolein-modified proteins using immunoblot assay. ${ }^{47,48}$ To visualized the accumulation of acroleinmodified proteins, immunohistochemical staining can be used with the same antibody against the acrolein-modified proteins. ${ }^{47,48}$

8-Iso-prostaglandin $F_{2 \alpha}$. 8 -Iso-prostaglandin $\mathrm{F}_{2 \alpha}$ is an isoprostane that has been shown to be useful for assessing oxidative stress in spinal cord ischemia. ${ }^{49}$ It is a biologically stable end-product of the free radical-induced oxidation of arachidonic acid produced from non-cyclooxygenase and cyclooxygenase peroxidation pathways. It appears in normal plasma and urine samples and is elevated by oxidative stress. Determination of 8 -iso-prostaglandin $\mathrm{F}_{2 \alpha}$ has been proposed as a reliable index of oxidative stress during SCI. ${ }^{50}$

Several different techniques have been used to assay 8-iso-prostaglandin $\mathrm{F}_{2 \alpha}$. These include gas chromatography-mass spectrometry, enzyme immunoassay and radioimmunoassay. Recently, Basu ${ }^{50}$ has raised an antibody specific for 8-iso-prostaglandin $\mathrm{F}_{2 \alpha}$ and developed 
an enzyme-linked immunosorbent assay for the measurement of 8iso-prostaglandin $\mathrm{F}_{2 \alpha}$ in biological fluids. In experimental spinal cord ischemia, a significant and immediate increase of 8-iso-prostaglandin $\mathrm{F}_{2 \alpha}$ in plasma at the start and up to $60 \mathrm{~min}$, and in the urine at 90 50 min was observed, indicating a consequence of oxidative injury. ${ }^{49}$ Compared with other assays, the greatest advantage of this immunoassay is that the level of 8-iso-prostaglandin $\mathrm{F}_{2 \alpha}$ is sufficient to be detected in every normal biological fluid, and the limit of detection is down to 23 pmoll $^{-1}$.

\section{Antioxidant-based strategies for intervention of SCI}

The involvement of ROS in the pathogenesis of SCI has prompted extensive studies on the neuroprotective effects of various compounds with antioxidative properties in animal models of SCI. It is possible that the use of certain antioxidants may slow the progression of spinal cord damage. This section begins with a description of $\mathrm{Cu}, \mathrm{ZnSOD}$ in protecting against SCI followed by summarizing the major recent findings on SCI protection by some non-protein compounds with antioxidant properties.

$\mathrm{Cu}, \mathrm{ZnSOD}$. ALS is a fatal motor neuron degenerative disease characterized by a loss of motor neurons in the central nervous system including spinal cord. Among all of the familial ALS patients, 20-30\% of them have point mutations in the gene that encodes $\mathrm{Cu}, \mathrm{ZnSOD}{ }^{43}$ Over 100 different missense substitutions in the 153-amino acid $\mathrm{Cu}, \mathrm{ZnSOD}$ have been described in individuals and kindreds affected by $\mathrm{Cu}, \mathrm{ZnSOD}$-linked familial ALS. ${ }^{51}$ Bowling et al. ${ }^{44}$ reported that cytosolic SOD activity, which was primarily $\mathrm{Cu}, \mathrm{ZnSOD}$ activity, was reduced significantly in familial ALS with SOD1 mutations. Therefore, $\mathrm{Cu}, \mathrm{ZnSOD}$ is likely an important therapeutic target that protects neurons from ROS damage after SCI. Utilizing Cu,ZnSOD-overexpressing transgenic rats and a mild spinal cord compression model to induce selective death of ventral horn motor neurons, Sugawara et al. ${ }^{52}$ reported that overexpression of $\mathrm{Cu}, \mathrm{ZnSOD}$ reduced both the production of superoxide at an early stage after SCI and the subsequent ROSmediated death of ventral horn motor neurons, supporting that $\mathrm{Cu}, \mathrm{ZnSOD}$ is a potential therapeutic agent. However, it is important to note the overexpression of antioxidant enzymes via genetic approaches is currently not practical for the intervention of human SCI. In this context, PEP-1, a 21-residue peptide carrier, has been developed for efficiently delivering $\mathrm{Cu}, \mathrm{ZnSOD}$ fusion protein into cultured neurons and injured spinal cord in vivo. ${ }^{22}$ Systemic administration of the fusion PEP-1-Cu,ZnSOD1 protein protected motor neurons from ROS damage and improved recovery after SCI. ${ }^{22}$ These findings suggest that PEP-1-Cu,ZnSOD may represent a new strategy for delivery of antioxidant enzymes for therapeutic intervention of SCI.

Non-protein compounds with antioxidant properties. Vitamin E: Vitamin $\mathrm{E}$ is an excellent antioxidant because it is a biological compound that is naturally present in animal and human tissues. It can cross intact cell membranes and has a long half-life and good bioavailability. Pretreatment with vitamin $\mathrm{E}$ has been shown to be protective in animal models of SCI. ${ }^{2,53}$ Iwasa et al. systemically studied the effects of vitamin $\mathrm{E}$ on injury of the spinal cord associated with ischemia in rats. ${ }^{54,55}$ The results showed that the motor disturbance induced by SCI was greatly reduced and spinal cord blood flow was promptly restored and remained normal after injury in the vitamin E-supplemented group. Tariq et al. ${ }^{56}$ have demonstrated that diabetic animals are more susceptible to compressive SCI as compared with nondiabetic animals most likely resulting from the higher depletion of vitamin $\mathrm{E}$ and glutathione in diabetic rats. Wang et al. ${ }^{57}$ reported that vitamin E feeding attenuated some of the detrimental effects of SCI on sperm functions and male accessory glands in rats, supporting a role of ROS-related events in deterioration of SCI.

Methylprednisolone: Methylprednisolone is a synthetic glucocorticoid steroid with potent anti-inflammatory activities. Methylprednisolone has been shown to also inhibit lipid peroxidation in vitro. ${ }^{2}$ Compression trauma of the cat spinal cord is known to induce a very rapid alteration in the lipid metabolism of cellular membranes leading to the secondary development of tissue ionic imbalance, ischemia, edema and inflammation. ${ }^{2}$ Studies demonstrated that pretreatment of cats with methylprednisolone $\left(15-30 \mathrm{mg} \mathrm{kg}^{-1}\right.$, i.v.) soon after blunt SCI decreased posttraumatic lipid peroxidation as measured by various biochemical indices. ${ }^{23-25}$ In addition to its ability to inhibit lipid peroxidation, methylprednisolone at high dose $\left(30 \mathrm{mg} \mathrm{kg}^{-1}\right.$, i.v. $)$ has been shown to support energy metabolism, prevent progressive posttraumatic ischemia development, reverse intracellular calcium accumulation, ameliorate neurofilament degradation and inhibit membrane lipid hydrolysis. ${ }^{2}$ These actions could lead to an attenuation of posttraumatic neuronal degeneration after the injured spinal cord. However, when used at high dosage for extended period of time, methylprednisolone causes serious side effects, including weight gain, glaucoma, osteoporosis and psychosis. Despite the above adverse effects, methylprednisolone treatment has been shown to be beneficial in patients with SCI.

21-Aminosteroids: 21-Aminosteroids are methylprednisolone derivatives. Compared with methylprednisolone, 21-aminosteroids lack the glucocorticoid side effects that limit the clinical usefulness of highdose methylprednisolone. The compound U-74006F is one of a series of 21-aminosteroids, which has been specifically developed for acute treatment of central nervous system trauma and ischemia due to its potent inhibition of lipid peroxidation.,26 U-72099E has been shown to be more potent than methylprednisolone in protecting rat brain synaptosomes from lipid peroxidation-induced inhibition of ${ }^{14} \mathrm{C}$-GABA uptake. ${ }^{2,26}$ In addition, it equaled the ability of methylprednisolone to enhance the early neurological recovery of head injured mice. ${ }^{2}$ The dose-response characteristics and capability of U-74006F to promote functional recovery in cats subjected to compression trauma of the upper lumbar (L-2) spinal cord have also been evaluated. ${ }^{58}$ Results showed that over a 100 -fold range of doses, $\mathrm{U}-74006 \mathrm{~F}$ has a remarkable capacity to promote functional recovery in spinal cord injured cats. The mechanism of protective action of $\mathrm{U}-74006 \mathrm{~F}$ against SCI is believed to involve an inhibition of oxygen radical-mediated lipid peroxidation. In vivo studies have demonstrated that $\mathrm{U}-74006 \mathrm{~F}$ can preserve tissue vitamin $\mathrm{E}$ levels in central nervous system trauma. ${ }^{59}$ In a manner similar to vitamin E, U-74006F has been found to scavenge lipid peroxyl radical thereby inhibiting lipid radical chain reactions. ${ }^{26} \mathrm{U}-74006 \mathrm{~F}$ also decreased hydroxyl radical formation from Fenton reactions like due to its ability to chelate redox-active iron. ${ }^{2}$

3H-1,2-dithiole-3-thione: as noted earlier, the central nervous system is particularly vulnerable to oxidative stress due to many intrinsic factors. Notably, the central nervous system also has relatively low glutathione levels compared with the other organs such as the liver. Because the coordinated actions of glutathione and a spectrum of other cellular antioxidative enzymes are essential for efficient detoxification of ROS that participate in the pathogenesis of SCI, we propose a novel strategy for protective/therapeutic intervention of SCI through coordinated upregulation of endogenous antioxidants in the neuronal cells mediated by $3 H$-1,2-dithiole-3-thione (D3T). D3T is a constituent of cruciferous vegetables. We have recently reported 
Table 1 Other major agents shown to be protective against $\mathrm{SCl}$ in experimental models

Agents
Scutellaria baicalensis (EESB), a herbal
remedies in oriental
Medicine

A novel peptide antioxidant (SS-31)

\section{Polyethylene glycol (PEG), a hydrophilic polymer \\ Edaravone (3-methyl-1-phenyl-pyrazo- lin-5-one), a newly developed radical scavenging agent 2,4-Dinitrophenol (DNP), a mitochon- drial uncoupling agent}

Hypericum perforatum, a medicinal plant species containing many polyphenolic compounds

\section{H-290/51, an antioxidant compound}

A rat model of $\mathrm{SCl}$

Alpha-Phenyl-N-tert-butyl Nitrone (PBN), a free radical scavenger

Tetramethylpyrazine (TMP)

Resveratrol, a natural phenolic compound

Resveratrol

U74389F, a compound in a family

of 21-aminosteroids that inhibit

lipid peroxidation

Neu2000, a novel NMDA antagonist and A rat model of moderate SCI antioxidant

Quercetin, a flavonol

A rat model of $\mathrm{SCl}$

Curcumin, a member of the ginger

family (Zingiberaceae)

Caffeic acid phenethyl ester (CAPE), a A rat model of SCl component of propolis

Epigallocatechin Gallate (EGCG)

A rat model of $\mathrm{SCl}$

NAC ( $N$-acetyl-cysteine), a precursor to glutathione

Baicalin (BC), a flavone spinal cord contusion injury

A rat model of severe $\mathrm{SCl}$ reperfusion injury

A rat model of $\mathrm{SCl}$

A rabbit model of $\mathrm{SCl}$

A rat model of $\mathrm{SCl}$ reperfusion (I-R)

A rat model of $\mathrm{SCl}$
Experimental models

Results /mechanisms of action

EESB treatment significantly improved functional recovery by inhibiting Reference

66 model following a spinal cord contusion inflammation and oxidative stress after injury both in vivo and in vitro. injury

In vitro and in the G93A mouse model of Administration of SS-31 in G93A ALS mice before the onset of symptoms 67 amyotrophic lateral sclerosis (ALS) led to a significant increase in survival and improvement of motor performance.

SS-31-treated mice showed a decreased cell loss and a decrease in immunostaining for markers of oxidative stress in the lumbar spinal cord. PEG treatment decreased ROS elevation and lipid peroxidation induced by 68 $\mathrm{SCl}$, possible through inhibiting superoxide mechanism.

Pretreatment with edaravone significantly improved motor dysfunction and 69 ameliorated tissue damage by scavenging ROS, especially in the neurons, after $\mathrm{SCl}$.

Rat model following a mild to moderate Pretreatment with DNP maintained mitochondrial bioenergetics and significantly decreased ROS levels, lipid peroxidation, and protein carbonyl content following $\mathrm{SCl}$.

An experimental mouse model of $\mathrm{SCl}$ Hypericum perforatum ( $30 \mathrm{mg} \mathrm{kg}^{-1} \mathrm{bw}$ ) has strong anti-inflammatory properties resulting in a reduced histological damage, polymorphonuclear leukocyte infiltration, formation of PAR and nitrotyrosine, STAT-3 activation, NF- $\mathrm{KB}$ activation, and degree of apoptosis.

Treatment with $\mathrm{H}-290 / 51$ (50 $\mathrm{mg} \mathrm{kg}^{-1}$, p.o.) 10 and 30 min after $\mathrm{SCl}$ markedly attenuated c-fos expression and motor dysfunction suggesting that this antioxidant is capable of attenuating cellular and molecular events following trauma.

PBN pretreatment attenuates lactic acidosis and improves energy metabolism after severe $\mathrm{SCl}$ suggesting the amelioration of radical induced mitochondrial dysfunction.

In a rat model of spinal cord ischemia- Treatment with TMP exerted a neuroprotective effect against spinal cord ischemia-reperfusion injury.

Resveratrol significantly promotes the recovery of rat dorsal neuronal 75 function after $\mathrm{SCl}$, and this effect is related to its characteristics of antioxidation, anti-inflammation and anti-apoptosis. Prophylactic use of resveratrol reduced neurologic injury and provided 76 clinical improvement by attenuating the inflammatory milieu in the rabbit spinal cord ischemia/reperfusion model. The bolus administration of U74389F one hour after injury facilitates the 77 return of the spinal cord function as measured by the CSEPs in this compression model of acute spinal cord trauma.

Neu2000 treatment significantly reduced the production of mitochondrial- 78 free radicals and improved locomotor outcomes that were associated with a significant increase in the volume of spared spinal cord tissue.

Quercetin administration results in preservation of tissue bridges at the site 79 of injury. Treatment success depends on frequency of administration and overall dose.

Curcumin inhibited apoptosis and neuron loss, quenched astrocyte acti- $\quad 80$ vation, and significantly improved neurologic deficit 7 days after spinal cord hemisection.

CAPE enhanced the recovery of locomotor function and reduced the lesion 81 size while suppressing the expression of the mRNAs for a pro-inflammatory cytokine.

MDA levels were significantly decreased in EGCG treatment groups. EGCG 82 significantly reduced the percentage of lesion area and improved behavioral function than the trauma group.

NAC showed protective effects of the spinal cord.

A rabbit mode of spinal cord ischemia-
The BC therapy ( $100 \mathrm{mg} \mathrm{kg}^{-1}$ ) dramatically decreased the water content 84 of spinal cord tissue, the permeability of blood-spinal cord barrier, oxidant stress and proinflammatory cytokines expression. Also, the treatment with $\mathrm{BC}$ also significantly improved the recovery of limb function. 
Table 1 (Continued)

\begin{tabular}{|c|c|c|c|}
\hline Agents & Experimental models & Results /mechanisms of action & Reference \\
\hline Polyethylene glycol (PEG) & A rat model of $\mathrm{SCl}$ & $\begin{array}{l}\text { Post-SCI administration of PEG decreased lesion volume, increased neu- } \\
\text { rofilament-positive fibers and corticospinal tract fibers in the lesion, and } \\
\text { did not increase reactive gliosis. }\end{array}$ & 85 \\
\hline Taurine, a potent antioxidant & A rat model of $\mathrm{SCl}$ & $\begin{array}{l}\text { Taurine significantly decreased IL- } 6 \text { and MPO levels in a dose-dependent } \\
\text { manner and significantly reduced the phosphorylation of STAT3 and } \\
\text { expression of COX-2 after SCl compared to controls. }\end{array}$ & 86 \\
\hline Alpha-tocopherol & A rat model of $\mathrm{SCl}$ & $\begin{array}{l}\text { The administration of alpha-tocopherol significantly improved the mean } \\
\text { motor score compared with control group due to its antioxidant effect. }\end{array}$ & 87 \\
\hline Alpha-tocopherol & $\begin{array}{l}\text { In a rat model of spinal cord ischemia- } \\
\text { reperfusion injury }\end{array}$ & $\begin{array}{l}\text { Alpha-tocopherol administration improves the oxidative stress level and } \\
\text { significantly prevents the damage caused by spinal cord ischemia-reper- } \\
\text { fusion injury with subsequent recovery of both motor and sensory functions. }\end{array}$ & 88 \\
\hline $\begin{array}{l}\text { Methylprednisolone (MP) and the non- } \\
\text { glucocorticoid 21-aminosteroid tirilazad }\end{array}$ & Acute $\mathrm{SCl}$ & $\begin{array}{l}\text { Administration of these compounds has been demonstrated in the multi- } \\
\text { center NASCIS clinical trials to produce at least a modest improvement in } \\
\text { neurological recovery when administered within the first } 8 \text { hours after SCI. }\end{array}$ & 89 \\
\hline Curcumin & A rat model of $\mathrm{SCl}$ & $\begin{array}{l}\text { Curcumin administration increases SOD level and significantly prevents the } \\
\text { damage (decreased MDA level) compared to control group indicating that } \\
\text { curcumin effectively protects the spinal cord tissues against oxidative } \\
\text { damage. }\end{array}$ & 90 \\
\hline
\end{tabular}

Lipoid acid (LA)

High doses of vitamins $\mathrm{C}$ and $\mathrm{E}$ (100 mg kg $^{-1}$ day $^{-1}$ )

Aluminum

17beta-estradiol

Tadalafi

Acetyl-L-carnitine (ALC)

Sulforaphane

Deferoxamine

Epigallocatechin gallate (EGCG)

Infliximab

Baicalin (BC)

Ethyl pyruvate (EP)

Dantrolene

Melatonin

Octreotide and melatonin

Lecithinized superoxide dismutase

Polyunsaturated fatty acids.

Nigella sativa (NS)
In a rat model of spinal cord ischemiareperfusion injury

A rat model of $\mathrm{SCl}$

A rat model of $\mathrm{SCl}$

In a rat model of $\mathrm{SCl}$

In a rat model of $\mathrm{SCl}$

In a rat model of $\mathrm{SCl}$

A murine model of $\mathrm{SCl}$

In a rat model of $\mathrm{SCl}$

In a rat model of $\mathrm{SCl}$

A rabbit I/R model

In a rat model of $\mathrm{SCl}$

A rabbit model of $\mathrm{SCl}$

A rabbit model of $\mathrm{SCl}$

A rabbit model of $\mathrm{SCl}$

In a rat model of $\mathrm{SCl}$

In a rat model of $\mathrm{SCl}$

In a rat model of $\mathrm{SCl}$

In a rat model of $\mathrm{SCl}$
LA pretreatment reduced neurologic injury in the rats, most probably by maintaining the oxidant/anti-oxidant ion balance during spinal cord ischemia.

The use of vitamins $C$ and $E$ did not improve their neurological performance. However, histopathological examination showed that the inflammatory response was less intense following administration of the combination of vitamins $\mathrm{C}$ and $\mathrm{E}$.

Administration of aluminum significantly impaired the recovery following $\mathrm{SCl}$. Analysis of the results of the biochemical, electrophysiological, and histopathological studies also confirmed the deleterious effects of aluminum on recovery from $\mathrm{SCl}$ in rats.

17beta-estradiol protects schwann cell (SCs) against oxidative stress and 94 improves transplanted SC survival.

Tadalafil is beneficial in reducing the effects of injury to the spinal cord by 95 increasing tissue levels of NO and serum activity of SOD.

ALC treatment maintains mitochondrial bioenergetics following contusion 96 SCl.

Suforaphane decreases MMP-9, TNF-alpha expression and vascular per- $\quad 97$ meability changes following $\mathrm{SCl}$ in mice.

Deferoxamine reduced the levels of free iron and lipid peroxidation, and 98 improved the hind limb functional status of rats with $\mathrm{SCl}$.

EGCG is effective in protecting rat spinal cord from secondary injury by 99 reducing the percentage of lesion area and improving behavioral function. Infliximab protected the spinal cord against injury in a rabbit I/R model 100 with decreased level of MDA in the tissue.

$\mathrm{BC}$ treatment significantly decreased oxidative stress and attenuated the $\mathrm{SCl}$.

EP affords a strong protection against the transient spinal cord ischemic 101 injury through inhibition of HMGB1 release.

Dantrolene DNT treatment prevented lipid peroxidation by $\mathrm{SCl}$, and augmented endogenous enzymic or non-enzymic antioxidative defense systems.

Melatonin administration reduced the incidence of $\mathrm{SCl}$ with decreased MDA levels and increased glutathione in serum and tissue.

Melatonin was found to be superior to octreotide to attenuate the SCl. 104 Lecithinized superoxide dismutase suppressed neuronal death through 105 reducing oxidative stress.

Omega-3 PUF was found to be neuroprotective and omega-6 PUFAs had a 106 damaging effect after $\mathrm{SCl}$ in the adult rat.

NS treatment is beneficial in spinal cord tissue damage through reducing 107 oxidative stress. 
Table 1 (Continued)

\begin{tabular}{|c|c|c|c|}
\hline Agents & Experimental models & Results /mechanisms of action & Reference \\
\hline MnTBAP & In a rat model of $\mathrm{SCl}$ & $\begin{array}{l}\text { Treatments with the low doses of MnTBAP provide sustained neuropro- } \\
\text { tection by preventing oxidative stress. }\end{array}$ & 108 \\
\hline Ginkgo leaf extracts & In a rat model of $\mathrm{SCl}$ & $\begin{array}{l}\text { Ginkgo leaf extracts afford a strong protection against } \mathrm{SCI} \text { through reducing } \\
\text { lipid peroxidation injury and inhibiting apoptosis. }\end{array}$ & 109 \\
\hline $\begin{array}{l}\text { Resveratrol and methylprednisolone } \\
\text { (MP) }\end{array}$ & In a rat model of $\mathrm{SCl}$ & $\begin{array}{l}\text { Resveratrol treatment revealed better biochemical recovery in the acute } \\
\text { stage of trauma than MP treatment and combinations promise better } \\
\text { results as each drug has a different anti-oxidative mechanism of action. }\end{array}$ & 110 \\
\hline Ebselen & In a rat model of $\mathrm{SCl}$ & $\begin{array}{l}\text { Ebselen treatment decreased tissue MDA level and prevented inhibition } \\
\text { of the enzymes SOD, GSH-Px and CAT in the tissues induced by SCI. }\end{array}$ & 111 \\
\hline Glutathione monoethyl ester (GSHE) & In a rat model of $\mathrm{SCl}$ & $\begin{array}{l}\text { GSHE treatment improved functional outcome and red nuclei neuron } \\
\text { survival of } \mathrm{SCl} \text {. }\end{array}$ & 112 \\
\hline Polyethylene glycol (PEG). & In a guinea pig model of $\mathrm{SCl}$ & $\begin{array}{l}\text { PEG exerted its neuroprotective effect through direct interaction with } \\
\text { mitochondria and reducing oxidative stress. }\end{array}$ & 113 \\
\hline Resveratrol & A rabbit I/R model & $\begin{array}{l}\text { Resveratrol-induced neuroprotection is mediated by its antioxidant and NO } \\
\text { promoting properties. }\end{array}$ & 114 \\
\hline Melatonin, and oxytetracycline & In a rat model of $\mathrm{SCl}$ & $\begin{array}{l}\text { Melatonin and oxytetracycline are effective in preventing lipid peroxidation } \\
\text { in } \mathrm{SCl} \text {. }\end{array}$ & 115 \\
\hline $\mathrm{H}-290 / 51$ & In a rat model of $\mathrm{SCl}$ & $\begin{array}{l}\text { The antioxidant compound H-290151markedly attenuated the trauma- } \\
\text { induced oxidative stress. }\end{array}$ & 116 \\
\hline Glutathione & In a rat model of $\mathrm{SCl}$ & $\begin{array}{l}\text { Glutathione significantly attenuated LPO-mediated damage in acute phase } \\
\mathrm{SCl} \text {. }\end{array}$ & 117 \\
\hline BDNF & In a rat model of $\mathrm{SCl}$ & $\begin{array}{l}\text { Infusion of BDNF inhibited the acute down-regulation of CuZnSOD } \\
\text { expression. }\end{array}$ & 118 \\
\hline $\begin{array}{l}\text { Methylprednisolone (MP), tirilazad } \\
\text { mesylate (TM) and vitamin E }\end{array}$ & In a rat model of $\mathrm{SCl}$ & $\begin{array}{l}\text { Treatments of MP, TM and vitamin E afforded a protective effect against } \\
\mathrm{SCl} \text { in rats by their antioxidant effects. }\end{array}$ & 119 \\
\hline $\begin{array}{l}\text { Methylprednisolone sodium succinate } \\
\text { (MPSS). }\end{array}$ & In a rat model of $\mathrm{SCl}$ & $\begin{array}{l}\text { MPSS administration significantly decreased the level of lipid peroxidation } \\
\text { and protected spinal cord ultrastructure following SCl. }\end{array}$ & 120 \\
\hline Caffeic acid phenethyl ester (CAPE) & A rabbit I/R model & $\begin{array}{l}\text { CAPE protected the spinal cord from ischemia-reperfusion injury through } \\
\text { its antioxidant effect. }\end{array}$ & 121 \\
\hline Alpha-tocopherol & In a rat model of $\mathrm{SCl}$ & $\begin{array}{l}\text { Long term administration of alpha-tocopherol decreased lipid peroxidation } \\
\text { following acute spinal cord trauma. }\end{array}$ & 122 \\
\hline
\end{tabular}

Abbreviations: IL, interleukin; MDA, malondialdehyde; NF-kB; nuclear factor $\kappa B$; ROS, reactive oxygen species; SCI, spinal cord injury.

that D3T increases multiple cellular antioxidants including glutathione and NQO1, two crucial cellular defenses against oxidative and electrophilic stress in human neuroblastoma cells (SH-SY5Y), human primary neurons and astrocytes, suggesting that D3Tmediated antioxidant induction is not cell-type specific. ${ }^{60-62}$ In addition, D3T treatment of the neuronal cells also results in a marked elevation of glutathione content in the mitochondrial compartment, ${ }^{62}$ a critical intracellular target for oxidative and electrophilic stress. ${ }^{63}$ It is important to note that the D3T upregulated endogenous defenses are accompanied by increased cellular resistance to neurocytotoxicity elicited by ROS and several well-known neurotoxins including acrolein, suggesting a potential therapeutic value in SCI. ${ }^{60-62}$

Other compounds: several epidemiological studies have demonstrated that increased consumption of antioxidant-rich fruits and vegetables is associated with reduced risk of ischemic stroke, dementia and SCI. ${ }^{64,65}$ In this context, identification and study of the biologically active compounds may be of importance for developing strategies to inhibit, retard or reverse the pathophysiological processes underlying SCI. Beside the aforementioned agents with antioxidant properties for treating SCI, there are numerous dietary and botanical natural compounds in fruits, vegetable and plants (such as green tea compounds and herbal remedies) being actively investigated for their potential benefits in SCI. These include carotenoids and phenolic compounds. Carotenoids are ubiquitous in the plant kingdom, and as many as 1000 naturally occurring variants have been identified. Plant phenols are antioxidants by virtue of the hydrogen donating properties of the phenolic hydroxyl groups, and over 8000 plant phenols have been isolated. Dietary plants rich in these compounds include broccoli, brussel sprouts, cabbage, kale, cauliflower, carrots, onions, tomatoes, spinach, garlic and some herbal medicines. Additionally, some compounds found in these plants may improve the endogenous antioxidant defense through induction of antioxidant enzymes.

Table 1 lists some bioactive compounds derived from different sources showing benefits in protecting against oxidative stress underlying SCI. These compounds have been shown to suppress lipid peroxidation due to their antioxidant properties including scavenging ROS, chelating redox-active metal ions and inhibiting xanthine oxidase. However, the exact cell signaling pathways activated by these natural bioactive agents are still not clear, and each compound may act differently in different cells. Studies have suggested that the protective role of these compounds against oxidative stress damage is mediated, at least partially, by effects on signaling molecules including extracellular signal-regulated kinase, nuclear factor $\kappa \mathrm{B}$ and Nrf2. ${ }^{18,27-}$ 31 Nrf2 signaling appears to has a central role in regulating the induction of antioxidants by phenolic compounds. ${ }^{18,27-31}$

\section{CONCLUSION}

The central nervous system, including spinal cord is highly susceptible to free-radical-mediated damage due to its high lipid content and active oxygen metabolism. It has been demonstrated that ROS and 
oxidative stress have a significant role in the pathophysiology of SCI and are a hallmark of the secondary injury underlying SCI in animal models. Thus, alleviating oxidative stress of secondary injury process may represent an effective strategy for therapeutic intervention of SCI. In this regard, continued studies on bioactive compounds with ROSscavenging capacity may lead to the development of effective antioxidant-based modalities for treating SCI in human subjects.

\section{CONFLICT OF INTEREST}

The authors declare no conflict of interest.

1 Sekhon LH, Fehlings MG. Epidemiology, demographics, and pathophysiology of acute spinal cord injury. Spine (Phila Pa 1976) 2001; 26(24 Suppl): S2-S12.

2 Hall ED, Yonkers PA, Andrus PK, Cox JW, Anderson DK. Biochemistry and pharmacology of lipid antioxidants in acute brain and spinal cord injury. J Neurotrauma 1992; 9(Suppl): S425-S442.

3 Hamann K, Durkes A, Ouyang H, Uchida K, Pond A, Shi R. Critical role of acrolein in secondary injury following ex vivo spinal cord trauma. J Neurochem 2008; 107: $712-721$.

4 Taoka Y, Okajima K, Uchiba M, Murakami K, Kushimoto S, Johno M et al. Gabexate mesilate, a synthetic protease inhibitor, prevents compression-induced spinal cord injury by inhibiting activation of leukocytes in rats. Crit Care Med 1997; 25: 874-879.

5 Jackson JH, Schraufstatter IU, Hyslop PA, Vosbeck K, Sauerheber R, Weitzman SA et al. Role of hydroxyl radical in DNA damage. Trans Assoc Am Phys 1987; 100: 147-157.

6 Muindi JR, Sinha BK, Gianni L, Myers CE. Hydroxyl radical production and DNA damage induced by anthracycline-iron complex. FEBS Lett 1984; 172 : 226-230.

7 Muller K, Gurster D. Hydroxyl radical damage to DNA sugar and model membranes induced by anthralin (dithranol). Biochem Pharmacol 1993; 46: 1695-1704.

8 Liu D, Liu J, Sun D, Wen J. The time course of hydroxyl radical formation following spinal cord injury: the possible role of the iron-catalyzed Haber-Weiss reaction. J Neurotrauma 2004; 21: 805-816.

9 Taoka $\mathrm{Y}$, Naruo M, Koyanagi E, Urakado M, Inoue M. Superoxide radicals play important roles in the pathogenesis of spinal cord injury. Paraplegia 1995; 33: 450-453.

10 Wingrave JM, Schaecher KE, Sribnick EA, Wilford GG, Ray SK, Hazen-Martin DJ et al. Early induction of secondary injury factors causing activation of calpain and mitochondria-mediated neuronal apoptosis following spinal cord injury in rats. $J$ Neurosci Res 2003; 73: 95-104.

11 Kocogullari CU, Becit N, Erkut B, Keles MS, Ceviz M, Ates A et al. Prevention of reperfusion injury of the spinal cord in aortic surgery: an experimental study. Surg Today 2008; 38: 237-244.

12 Storey KB. Oxidative stress: animal adaptations in nature. Braz J Med Biol Res 1996; 29: 1715-1733.

13 Fridovich I. Superoxide radical and superoxide dismutases. Annu Rev Biochem 1995; 64: 97-112.

14 Lucas JH, Wheeler DG, Guan Z, Suntres Z, Stokes BT. Effect of glutathione augmentation on lipid peroxidation after spinal cord injury. J Neurotrauma 2002; 19: 763-775.

15 Elshafey A, Lanyon WG, Connor JM. Identification of a new missense point mutation in exon 4 of the Cu/Zn superoxide dismutase (SOD-1) gene in a family with amyotrophic lateral sclerosis. Hum Mol Genet 1994; 3: 363-364.

16 Grabitz K, Freye E, Prior R, Kolvenbach R, Sandmann W. The role of superoxide dismutase (SOD) in preventing postischemic spinal cord injury. Adv Exp Med Biol 1990; 264: 13-16.

17 Ross D. Quinone reductases multitasking in the metabolic world. Drug Metab Rev 2004; 36: 639-654.

18 Duan W, Zhang R, Guo Y, Jiang Y, Huang Y, Jiang $\mathrm{H}$ et al. Nrf2 activity is lost in the spinal cord and its astrocytes of aged mice. In Vitro Cell Dev Biol Anim 2009; 45: 388-397.

19 Ross D, Kepa JK, Winski SL, Beall HD, Anwar A, Siegel D. NAD(P)H:quinone oxidoreductase 1 (NQO1): chemoprotection, bioactivation, gene regulation and genetic polymorphisms. Chem Biol Interact 2000; 129: 77-97.

20 Siegel D, Bolton EM, Burr JA, Liebler DC, Ross D. The reduction of alpha-tocopherolquinone by human $\mathrm{NAD}(\mathrm{P}) \mathrm{H}$ : quinone oxidoreductase: the role of alpha-tocopherolhydroquinone as a cellular antioxidant. Mol Pharmacol 1997; 52: 300-305.

21 Julien JP. Amyotrophic lateral sclerosis. unfolding the toxicity of the misfolded. Cell 2001; 104: 581-591.

22 Yune TY, Lee JY, Jiang MH, Kim DW, Choi SY, Oh TH. Systemic administration of PEP$1-S O D 1$ fusion protein improves functional recovery by inhibition of neuronal cell death after spinal cord injury. Free Radic Biol Med 2008; 45: 1190-1200.

23 Hall ED, Braughler JM. Effects of intravenous methylprednisolone on spinal cord lipid peroxidation and $\mathrm{Na}++\mathrm{K}+$ )-ATPase activity. Dose-response analysis during 1st hour after contusion injury in the cat. J Neurosurg 1982; 57: 247-253.
24 Demopoulos HB, Flamm ES, Seligman ML, Pietronigro DD, Tomasula J, DeCrescito V. Further studies on free-radical pathology in the major central nervous system disorders: effect of very high doses of methylprednisolone on the functional outcome, morphology, and chemistry of experimental spinal cord impact injury. Can J Physiol Pharmacol 1982; 60: 1415-1424.

25 Anderson DK, Saunders RD, Demediuk P, Dugan LL, Braughler JM, Hall ED et al. Lipid hydrolysis and peroxidation in injured spinal cord: partial protection with methylprednisolone or vitamin E and selenium. Cent Nerv Syst Trauma 1985; 2: 257-267.

26 Braughler JM, Pregenzer JF, Chase RL, Duncan LA, Jacobsen EJ, McCall JM. Novel 21-amino steroids as potent inhibitors of iron-dependent lipid peroxidation. J Biol Chem 1987; 262: 10438-10440.

27 Nguyen T, Sherratt PJ, Pickett CB. Regulatory mechanisms controlling gene expression mediated by the antioxidant response element. Annu Rev Pharmacol Toxicol 2003; 43: 233-260.

28 Motohashi H, Yamamoto M. Nrf2-Keap1 defines a physiologically important stress response mechanism. Trends Mol Med 2004; 10: 549-557.

29 Li J, Johnson D, Calkins M, Wright L, Svendsen C, Johnson J. Stabilization of Nrf2 by tBHQ confers protection against oxidative stress-induced cell death in human neural stem cells. Toxicol Sci 2005; 83: 313-328.

30 Kraft AD, Resch JM, Johnson DA, Johnson JA. Activation of the Nrf2-ARE pathway in muscle and spinal cord during ALS-like pathology in mice expressing mutant SOD1. Exp Neurol 2007; 207: 107-117.

31 Vargas MR, Pehar M, Cassina P, Martinez-Palma L, Thompson JA, Beckman JS et al. Fibroblast growth factor-1 induces heme oxygenase-1 via nuclear factor erythroid 2related factor 2 (Nrf2) in spinal cord astrocytes: consequences for motor neuron survival. J Biol Chem 2005; 280: 25571-25579.

32 Dickinson DA, Forman HJ. Glutathione in defense and signaling: lessons from a small thiol. Ann NY Acad Sci 2002; 973: 488-504.

33 Logan MP, Parker S, Shi R. Glutathione and ascorbic acid enhance recovery of Guinea pig spinal cord white matter following ischemia and acrolein exposure. Pathobiology 2005; 72: 171-178.

34 Vaziri ND, Lee YS, Lin CY, Lin VW, Sindhu RK. NAD(P)H oxidase, superoxide dismutase, catalase, glutathione peroxidase and nitric oxide synthase expression in subacute spinal cord injury. Brain Res 2004; 995: 76-83.

35 Loguercio C, Di Cosmo A, De Santis A, Nardi G. Glutathione suppresses spontaneous activity in the frog spinal cord. Neuroreport 1995; 6: 1669-1673.

36 Guo N, McIntosh C, Shaw C. Glutathione: new candidate neuropeptide in the central nervous system. Neuroscience 1992; 51: 835-842.

37 Kamencic H, Griebel RW, Lyon AW, Paterson PG, Juurlink BH. Promoting glutathione synthesis after spinal cord trauma decreases secondary damage and promotes retention of function. FASEB J 2001; 15: 243-250.

38 Boutolleau D, Lefevre G, Etienne J. Determination of glutathione with the GSH-400 method: value of derivative spectrophotometry]. Ann Biol Clin (Paris) 1997; 55: 592-596.

39 Eady JJ, Orta T, Dennis MF, Stratford MR, Peacock JH. Glutathione determination by the Tietze enzymatic recycling assay and its relationship to cellular radiation response. Br J Cancer 1995; 72: 1089-1095.

40 Hissin PJ, Hilf R. A fluorometric method for determination of oxidized and reduced glutathione in tissues. Anal Biochem 1976; 74: 214-226.

41 Cohn VH, Lyle J. A fluorometric assay for glutathione. Anal Biochem 1966; 14 : 434-440.

42 Jia Z, Saha S, Zhu H, Li Y. Spectrofluorometric Measurement of Reduced Glutathione Levels in Human Neuronal Cells. Mary Ann Liebert: New York, 2009.

43 Rosen DR, Siddique T, Patterson D, Figlewicz DA, Sapp P, Hentati A et al. Mutations in $\mathrm{Cu} / \mathrm{Zn}$ superoxide dismutase gene are associated with familial amyotrophic lateral sclerosis. Nature 1993; 362: 59-62.

44 Bowling AC, Schulz JB, Brown Jr RH, Beal MF. Superoxide dismutase activity, oxidative damage, and mitochondrial energy metabolism in familial and sporadic amyotrophic lateral sclerosis. J Neurochem 1993; 61: 2322-2325.

45 Hamann K, Shi R. Acrolein scavenging: a potential novel mechanism of attenuating oxidative stress following spinal cord injury. J Neurochem 2009; 111: 1348-1356.

46 Luo J, Shi R. Acrolein induces axolemmal disruption, oxidative stress, and mitochondrial impairment in spinal cord tissue. Neurochem Int 2004; 44: 475-486.

47 Uchida K, Kanematsu M, Sakai K, Matsuda T, Hattori N, Mizuno Y et al. Protein-bound acrolein: potential markers for oxidative stress. Proc Natl Acad Sci USA 1998; 95: 4882-4887.

48 Luo J, Uchida K, Shi R. Accumulation of acrolein-protein adducts after traumatic spinal cord injury. Neurochem Res 2005; 30: 291-295.

49 Basu S, Hellberg A, Ulus AT, Westman J, Karacagil S. Biomarkers of free radical injury during spinal cord ischemia. FEBS Lett 2001; 508: 36-38.

50 Basu S. Measurement of F2-Isoprostanes in Tissues and Biological Fluids as an vivo Index of Oxidative Stress. Mary Ann Liebert: New York, 2009.

51 Poon HF, Hensley K, Thongboonkerd V, Merchant ML, Lynn BC, Pierce WM et al. Redox proteomics analysis of oxidatively modified proteins in G93A-SOD1 transgenic mice - a model of familial amyotrophic lateral sclerosis. Free Radic Biol Med 2005; 39: 453-462.

52 Sugawara T, Lewen A, Gasche Y, Yu F, Chan PH. Overexpression of SOD1 protects vulnerable motor neurons after spinal cord injury by attenuating mitochondrial cytochrome c release. FASEB J 2002; 16: 1997-1999.

53 Hall ED, Wolf DL. A pharmacological analysis of the pathophysiological mechanisms of posttraumatic spinal cord ischemia. J Neurosurg 1986; 64: 951-961. 
54 Iwasa K, Ikata T. An experimental study on preventive effect of vitamin E in spinal cord injury. Nippon Seikeigeka Gakkai Zasshi 1988; 62: 767-775.

55 Iwasa K, Ikata T, Fukuzawa K. Protective effect of vitamin E on spinal cord injury by compression and concurrent lipid peroxidation. Free Radic Biol Med 1989; 6: 599-606.

56 Tariq M, Morais C, Kishore PN, Biary N, Al Deeb S, Al Moutaery K. Neurological recovery in diabetic rats following spinal cord injury. J Neurotrauma 1998; 15: 239-251.

57 Wang S, Wang G, Barton BE, Murphy TF, Huang HF. Beneficial effects of vitamin E in sperm functions in the rat after spinal cord injury. J Androl 2007; 28: 334-341.

58 Anderson DK, Braughler JM, Hall ED, Waters TR, McCall JM, Means ED. Effects of treatment with $\mathrm{U}-74006 \mathrm{~F}$ on neurological outcome following experimental spinal cord injury. J Neurosurg 1988; 69: 562-567.

59 Hall ED, Braughler JM. Central nervous system trauma and stroke. II. Physiological and pharmacological evidence for involvement of oxygen radicals and lipid peroxidation. Free Radic Biol Med 1989; 6: 303-313.

60 Jia Z, Misra BR, Zhu H, Li Y, Misra HP. Upregulation of cellular glutathione by 3H-1,2dithiole-3-thione as a possible treatment strategy for protecting against acroleininduced neurocytotoxicity. Neurotoxicology 2009; 30: 1-9.

61 Jia Z, Zhu H, Li Y, Misra HP. Cruciferous nutraceutical 3H-1,2-dithiole-3-thione protects human primary astrocytes against neurocytotoxicity elicited by MPTP, MPP(+), 6-OHDA, HNE and acrolein. Neurochem Res 2009; 34: 1924-1934.

62 Jia Z, Zhu H, Misra HP, Li Y. Potent induction of total cellular GSH and NQO1 as well as mitochondrial GSH by 3H-1,2-dithiole-3-thione in SH-SY5Y neuroblastoma cells and primary human neurons: protection against neurocytotoxicity elicited by dopamine, 6-hydroxydopamine, 4-hydroxy-2-nonenal, or hydrogen peroxide. Brain Res 2008; 1197: 159-169.

63 Beal MF. Mitochondria, oxidative damage, and inflammation in Parkinson's disease. Ann NY Acad Sci 2003; 991: 120-131.

64 Joshipura KJ, Ascherio A, Manson JE, Stampfer MJ, Rimm EB, Speizer FE et al. Fruit and vegetable intake in relation to risk of ischemic stroke. JAMA 1999; 282: 1233-1239.

65 Reid G, Hsiehl J, Potter P, Mighton J, Lam D, Warren D et al. Cranberry juice consumption may reduce biofilms on uroepithelial cells: pilot study in spinal cord injured patients. Spinal Cord 2001; 39: 26-30.

66 Yune TY, Lee JY, Cui CM, Kim HC, Oh TH. Neuroprotective effect of Scutellaria baicalensis on spinal cord injury in rats. J Neurochem 2009; 110: 1276-1287.

67 Petri S, Kiaei M, Damiano M, Hiller A, Wille E, Manfredi G et al. Cell-permeable peptide antioxidants as a novel therapeutic approach in a mouse model of amyotrophic lateral sclerosis. J Neurochem 2006; 98: 1141-1148.

68 Luo J, Borgens R, Shi R. Polyethylene glycol immediately repairs neuronal membranes and inhibits free radical production after acute spinal cord injury. J Neurochem 2002; 83: $471-480$.

69 Aoyama T, Hida K, Kuroda S, Seki T, Yano S, Shichinohe $\mathrm{H}$ et al. Edaravone ( $\mathrm{MCl}-186)$ scavenges reactive oxygen species and ameliorates tissue damage in the murine spinal cord injury model. Neurol Med Chir (Tokyo) 2008; 48: 539-545; discussion 545.

70 Jin Y, McEwen ML, Nottingham SA, Maragos WF, Dragicevic NB, Sullivan PG et al. The mitochondrial uncoupling agent 2,4-dinitrophenol improves mitochondrial function, attenuates oxidative damage, and increases white matter sparing in the contused spinal cord. J Neurotrauma 2004; 21: 1396-1404.

71 Genovese T, Mazzon E, Menegazzi M, Di Paola R, Muia C, Crisafulli C et al. Neuroprotection and enhanced recovery with hypericum perforatum extract after experimental spinal cord injury in mice. Shock 2006; 25: 608-617.

72 Sharma HS, Sjoquist PO, Mohanty S, Wiklund L. Post-injury treatment with a new antioxidant compound $\mathrm{H}-290 / 51$ attenuates spinal cord trauma-induced c-fos expression, motor dysfunction, edema formation, and cell injury in the rat. Acta Neurochir Supp/ 2006; 96: 322-328.

73 Farooque M, Olsson Y, Hillered L. Pretreatment with alpha-phenyl-N-tert-butyl-nitrone (PBN) improves energy metabolism after spinal cord injury in rats. J Neurotrauma 1997; 14: 469-476.

74 Fan L, Wang K, Shi Z, Die J, Wang C, Dang X. Tetramethylpyrazine protects spinal cord and reduces inflammation in a rat model of spinal cord ischemia-reperfusion injury. J Vasc Surg 2011; 54: 192-200.

75 Liu C, Shi Z, Fan L, Zhang C, Wang K, Wang B. Resveratrol improves neuron protection and functional recovery in rat model of spinal cord injury. Brain Res 2011; 1374: 100-109.

76 Kaplan S, Bisleri G, Morgan JA, Cheema FH, Oz MC. Resveratrol, a natural red wine polyphenol, reduces ischemia-reperfusion-induced spinal cord injury. Ann Thorac Surg 2005; 80: 2242-2249.

77 Haghighi SS, Hall ED, Geng XZ, Oro JJ, Johnson GC. Therapeutic value of 21-aminosteroid U74389F in acute spinal cord injury. Neurol Res 1993; 15: 321-326.

78 Springer JE, Rao RR, Lim HR, Cho SI, Moon GJ, Lee HY et al. The functional and neuroprotective actions of Neu2000, a dual-acting pharmacological agent, in the treatment of acute spinal cord injury. J Neurotrauma 2010; 27: 139-149.

79 Schultke E, Kamencic H, Skihar VM, Griebel R, Juurlink B. Quercetin in an animal model of spinal cord compression injury: correlation of treatment duration with recovery of motor function. Spinal Cord 2010; 48: 112-117.

80 Lin MS, Lee YH, Chiu WT, Hung KS. Curcumin provides neuroprotection after spinal cord injury. J Surg Res 2011; 166: 280-289.

81 Kasai M, Fukumitsu H, Soumiya H, Furukawa S. Caffeic acid phenethyl ester reduces spinal cord injury-evoked locomotor dysfunction. Biomed Res 2011; 32: 1-7.
82 Khalatbary AR, Tiraihi T, Boroujeni MB, Ahmadvand H, Tavafi M, Tamjidipoor A. Effects of epigallocatechin gallate on tissue protection and functional recovery after contusive spinal cord injury in rats. Brain Res 2010; 1306: 168-175.

83 Cakir O, Erdem K, Oruc A, Kilinc N, Eren N. Neuroprotective effect of N-acetylcysteine and hypothermia on the spinal cord ischemia-reperfusion injury. Cardiovasc Surg 2003; 11: 375-379.

84 Cao Y, Li G, Wang YF, Fan ZK, Yu DS, Wang ZD et al. Neuroprotective effect of baicalin on compression spinal cord injury in rats. Brain Res 2010; 1357: 115-123.

85 Roman JA, Niedzielko TL, Haddon RC, Parpura V, Floyd CL. Single-walled carbon nanotubes chemically functionalized with polyethylene glycol promote tissue repair in a rat model of spinal cord injury. J Neurotrauma 2011 (in press)

86 Nakajima Y, Osuka K, Seki Y, Gupta RC, Hara M, Takayasu M et al. Taurine reduces inflammatory responses after spinal cord injury. J Neurotrauma 2010; 27: 403-410.

87 Al Jadid MS, Robert A, Al-Mubarak S. The efficacy of alpha-tocopherol in functional recovery of spinal cord injured rats: an experimental study. Spinal Cord 2009; 47: $662-667$.

88 Morsy MD, Mostafa OA, Hassan WN. A potential protective effect of alpha-tocopherol on vascular complication in spinal cord reperfusion injury in rats. J Biomed Sci 2010; 17: 55.

89 Hall ED. Antioxidant therapies for acute spinal cord injury. Neurotherapeutics 2011; 8: 152-167.

90 Sahin Kavakli H, Koca C, Alici O. Antioxidant effects of curcumin in spinal cord injury in rats. Ulus Travma Acil Cerrahi Derg 2011; 17: 14-18.

91 Shaafi S, Afrooz MR, Hajipour B, Dadadshi A, Hosseinian MM, Khodadadi A. Antioxidative effect of lipoic Acid in spinal cord ischemia/reperfusion. Med Princ Pract 2011; 20: 19-22.

92 Cristante AF, Barros Filho TE, Oliveira RP, Marcon RM, Rocha ID, Hanania FR et al. Antioxidative therapy in contusion spinal cord injury. Spinal Cord 2009; 47: 458-463.

93 Al Moutaery K, Al Deeb S, Biary N, Morais C, Ahmad Khan H, Tariq M. Effect of aluminum on neurological recovery in rats following spinal cord injury. $J$ Neurosurg 2000; 93 (2 Suppl): 276-282.

94 Siriphorn A, Chompoopong S, Floyd CL. 17beta-estradiol protects Schwann cells against $\mathrm{H} 2 \mathrm{O} 2$-induced cytotoxicity and increases transplanted Schwann cell survival in a cervical hemicontusion spinal cord injury model. J Neurochem 2010; 115: 864-872.

95 Serarslan Y, Yonden Z, Ozgiray E, Oktar S, Guven EO, Sogut S et al. Protective effects of tadalafil on experimental spinal cord injury in rats. J Clin Neurosci 2010; 17: 349-352.

96 Patel SP, Sullivan PG, Lyttle TS, Rabchevsky AG. Acetyl-L-carnitine ameliorates mitochondrial dysfunction following contusion spinal cord injury. J Neurochem 2010; 114: 291-301.

97 Mao L, Wang HD, Wang XL, Qiao L, Yin HX. Sulforaphane attenuates matrix metalloproteinase-9 expression following spinal cord injury in mice. Ann Clin Lab Sci 2010; 40: 354-360.

98 Liu J, Tang T, Yang H. Protective effect of deferoxamine on experimental spinal cord injury in rat. Injury 2011; 42: 742-745.

99 Khalatbary AR, Tiraihi T, Boroujeni MB, Ahmadvand H, Tavafi M, Tamjidipoor A. Effects of epigallocatechin gallate on tissue protection and functional recovery after contusive spinal cord injury in rats. Brain Res 2010; 1306: 168-175.

100 Guven C, Borcek AO, Cemil B, Kurt G, Yildirim Z, Ucankus NL et al. Neuroprotective effects of infliximab in experimental spinal cord ischemic injury. J Clin Neurosci 2010; 17: 1563-1567.

101 Wang Q, Ding Q, Zhou Y, Gou X, Hou L, Chen S et al. Ethyl pyruvate attenuates spinal cord ischemic injury with a wide therapeutic window through inhibiting high-mobility group box 1 release in rabbits. Anesthesiology 2009; 110: 1279-1286.

102 Aslan A, Cemek M, Buyukokuroglu ME, Altunbas K, Bas O, Yurumez Y et al. Dantrolene can reduce secondary damage after spinal cord injury. Eur Spine $J$ 2009; 18: 1442-1451.

103 Korkmaz A, Oyar EO, Kardes O, Omeroglu S. Effects of melatonin on ischemic spinal cord injury caused by aortic cross clamping in rabbits. Curr Neurovasc Res 2008; 5: 46-51.

104 Erol FS, Kaplan M, Tiftikci M, Yakar H, Ozercan I, Ilhan N et al. Comparison of the effects of octreotide and melatonin in preventing nerve injury in rats with experimental spinal cord injury. J Clin Neurosci 2008; 15: 784-790.

105 Takenaga M, Ohta Y, Tokura Y, Hamaguchi A, Nakamura M, Okano H et al. Lecithinized superoxide dismutase (PC-SOD) improved spinal cord injury-induced motor dysfunction through suppression of oxidative stress and enhancement of neurotrophic factor production. J Control Release 2006; 110: 283-289.

106 King VR, Huang WL, Dyall SC, Curran OE, Priestley JV, Michael-Titus AT. Omega-3 fatty acids improve recovery, whereas omega- 6 fatty acids worsen outcome, after spinal cord injury in the adult rat. J Neurosci 2006; 26: 4672-4680.

107 Kanter M, Coskun O, Kalayci M, Buyukbas S, Cagavi F. Neuroprotective effects of Nigella sativa on experimental spinal cord injury in rats. Hum Exp Toxicol 2006; 25: 127-133

108 Hachmeister JE, Valluru L, Bao F, Liu D. Mn (III) tetrakis (4-benzoic acid) porphyrin administered into the intrathecal space reduces oxidative damage and neuron death after spinal cord injury: a comparison with methylprednisolone. J Neurotrauma 2006; 23: $1766-1778$.

109 Fan LH, Wang KZ, Cheng B. Protective effects of ginkgo leaf extracts on neurons in spinal cord after ischemia-reperfusion injury in rabbits]. Zhong Xi Yi Jie He Xue Bao 2006; 4: 181-184. 
110 Ates O, Cayli S, Altinoz E, Gurses I, Yucel N, Kocak A et al. Effects of resveratrol and methylprednisolone on biochemical, neurobehavioral and histopathological recovery after experimental spinal cord injury. Acta Pharmacol Sin 2006; 27: 1317-1325.

111 Kalayci M, Coskun O, Cagavi F, Kanter M, Armutcu F, Gul S et al. Neuroprotective effects of ebselen on experimental spinal cord injury in rats. Neurochem Res 2005; 30: 403-410.

112 Guizar-Sahagun G, Ibarra A, Espitia A, Martinez A, Madrazo I, Franco-Bourland RE. Glutathione monoethyl ester improves functional recovery, enhances neuron survival, and stabilizes spinal cord blood flow after spinal cord injury in rats. Neuroscience 2005; 130: 639-649.

113 Luo J, Borgens R, Shi R. Polyethylene glycol improves function and reduces oxidative stress in synaptosomal preparations following spinal cord injury. J Neurotrauma 2004; 21: 994-1007.

114 Kiziltepe U, Turan NN, Han U, Ulus AT, Akar F. Resveratrol, a red wine polyphenol, protects spinal cord from ischemia-reperfusion injury. Journal of vascular surgery: official publication, the Society for Vascular Surgery [and] International Society for Cardiovascular Surgery, North American Chapter 2004; 40: 138-145.

115 Topsakal C, Kilic N, Ozveren F, Akdemir I, Kaplan M, Tiftikci M et al. Effects of prostaglandin E1, melatonin, and oxytetracycline on lipid peroxidation, antioxidant defense system, paraoxonase (PON1) activities, and homocysteine levels in an animal model of spinal cord injury. Spine 2003; 28: 1643-1652.

116 Sharma HS, Sjoquist PO, Alm P. A new antioxidant compound H-290151 attenuates spinal cord injury induced expression of constitutive and inducible isoforms of nitric oxide synthase and edema formation in the rat. Acta Neurochirurgica Supp/ 2003; 86: 415-420.

117 Lucas JH, Wheeler DG, Guan Z, Suntres Z, Stokes BT. Effect of glutathione augmentation on lipid peroxidation after spinal cord injury. J Neurotrauma 2002; 19: 763-775.

118 Ikeda O, Murakami M, Ino H, Yamazaki M, Koda M, Nakayama C et al. Effects of brain-derived neurotrophic factor (BDNF) on compression-induced spinal cord injury: BDNF attenuates down-regulation of superoxide dismutase expression and promotes up-regulation of myelin basic protein expression. J Neuropathol Exp Neurol 2002; 61: 142-153.

119 Koc RK, Akdemir H, Karakucuk El, Oktem IS, Menku A. Effect of methylprednisolone, tirilazad mesylate and vitamin $\mathrm{E}$ on lipid peroxidation after experimental spinal cord injury. Spinal cord: The Official Journal of the International Medical Society of Paraplegia 1999; 37: 29-32.

120 Kaptanoglu E, Caner HH, Surucu HS, Akbiyik F. Effect of mexiletine on lipid peroxidation and early ultrastructural findings in experimental spinal cord injury. $J$ Neurosurg 1999; 91 (2 Suppl): 200-204.

121 Ilhan A, Koltuksuz U, Ozen S, Uz E, Ciralik H, Akyol O. The effects of caffeic acid phenethyl ester (CAPE) on spinal cord ischemia/reperfusion injury in rabbits. Eur J Cardiothorac Surg 1999; 16: 458-463.

122 Bozbuga M, Izgi N, Canbolat A. The effects of chronic alpha-tocopherol administration on lipid peroxidation in an experimental model of acute spinal cord injury. Neurosurg Rev 1998; 21: 36-42. 